\title{
Research of Problems and Countermeasures on College File Management
}

\author{
Qiang Hua Li ${ }^{*}$ \\ Weihai Vocational College, China \\ liqianghua789@126.com
}

Keywords: File management; Situation analysis; Problems; Improvement measures; Colleges.

\begin{abstract}
College file management plays a more and more important role in colleges. Therefore, people pays more and more attention to file management. In the paper, problems in college file management is also proposed aiming at status of college file management at present, such as weak awareness of file management, incomplete file management system, delayed file management function, low management personnel quality, backward management information technology construction, etc. Corresponding improvement measures are proposed aiming at the problems. Suggestions are proposed for doing well in college file management, thereby ensuring better role of file management in college development.
\end{abstract}

\section{Introduction}

After education is lifted as national strategy due to high attention of the party and the state since reform and opening up, especially in the last decade, college file management work is gradually recognized and focused by the society. College file management shows unprecedented development momentum, which plays an important role in college teaching, development, research, school external contact, etc. Most colleges and universities have established file room or archives adapting to school development according to school condition. Appropriate rules and regulations are established. School leaders should be responsible for concrete management work. All departments and all specialties are provided with part-time principals engaged in file work. Tree-shaped management system of file management work is initially formed. In recent years, college files are sharply increased. Contents and forms are more and more complicated, thereby the applicable scope is expanded. Utilization forms are diversified for proposing new requirements on file management. In recent years, new concepts drives colleges to develop in discipline field construction, education form, etc., and file quantity is greatly increased. At present, college files mainly include long-term text files with file types: party management file, comprehensive materials which are directly formed in school party-mass and administrative management activities with storage value and superior material about party administrative work; teaching file, and materials which are directly formed in teaching management and teaching practical activities with storage value, student related material files during recruitment, enrollment, graduation, etc. Infrastructure, accounting and other files which must be saved for long time. The files are excessive, in addition file categories are complicated and diversified. Such as: electronic file category: office automation is becoming increasingly popular in various colleges and universities with the development of computer technology and communication technology, software platforms have been applied in many colleges in the aspects of teaching, research, government agencies and other work. Massive electronic documents can be produced in all platforms. These electronic documents are worthy of storage. Electronic documents are mainly stored in disk, tape and CD. physical file category refers to physical object formed in related school activities, such as pennants, trophies, awards and physical object produced in intercollegiate exchange. Physical file can reflect the practical value of files more vividly. School museum should be established with physical file as foundation, which can become beneficial window for school propaganda. The files also include teaching work, secondary college files, cooperative education, etc. File management is 
more complex and diversified. College file quantity and category are constantly increased, thereby proposing higher requirements on college files.

\section{Problems in File Management}

Weak Awareness in File Management. File work mainly serves political services for a long time due to various reasons. Therefore, files, the information resources plays narrow and shallow role in national economy and social development with low utilization efficiency, thereby severely reducing its role in social demand. Colleges are no exception, file management mode mainly depends on administrative development, which is not incorporated into legal management and scientific management scope. Saved data status quo shows that file materials with high technology contents in teaching and research are very low. Files in administrative management are more. The condition is slightly improved with release and implementation of 'Archives Act', which is far away from actual development of colleges.

Incomplete System of File Management. In recent years, file management rules and system construction in colleges have made great progress with continuous introduction of national 'Archives Act', 'College File Management Measures' and other file management rules. However, file management systems are still incomplete from the perspective of college file management work at present. Its specific manifestations lie in the following aspects: document management and file management department are separated without effective guidance and supervision system. System formation is disconnected with file archiving, thereby leading to incomplete file collection. Work conference about teaching, enrollment, graduation and other aspects should be held in the school each semester, which is lack of standardized meeting minutes. Young teachers should be trained with specific training plan and summary materials; part-time archivists in relevant department have inconsistent files, including the following performances: recording materials of students in various assessment, recognition, discipline violation, participation in social practice, practice, etc. are inconsistent in various departments. Student record management is not strict, and there is no strict concrete management system in student downgrading, graduation, dropout and change in other aspects. In addition, file management network shows that some schools do not establish standard department filing system (pre-filing system), special personnel are not appointed as part-time archivists responsible for collecting and archiving document materials. Personnel is temporarily arranged at the beginning of archiving in the second year in many occasions, and problems can not be solved. File material keeping utilization shows that there is not strict management in saving and utilizing materials, documents are randomly withdrawn when they are demanded, files are checked and borrowed without strict registration. Some files are not returned after long-term borrowing without return urging records, thereby some important files are lost. Files with special protection are not provided with concrete utilization and protection measures.

Delayed File Management Function. Currently, college file management can not freshly adapt to requirements and development of modern economy mode. One important factor is simple management function, which can not be compatible. For example, various personnel database, wage adjustment database and database for paying various insurances are frequently utilized in personnel management. The databases are respectively released from different superior administrative departments with different functions and different types. Current management data can not reach demanded requirements. Therefore, all school units only can check original file materials in individual utilization of personnel files. Personnel files can be damaged on one hand, files can not be utilized due to use authority, unnecessary trouble can be caused. Meanwhile, work load can be increased for file management personnel.

Management personnel quality should be improved. Currently, college file management personnel composition is more complex. Few personnel are provided with file professional knowledge. Quite a part of archivists are selected from other specialties especially from subordinate departments. Office secretaries basically occupy the posts as part-time job, who are lack of file 
professional knowledge and skills with low management integrated quality, thereby seriously affecting file management level. Meanwhile, some departments are provided with computers and other modern facilities. However, file workers are lack of modern facility utilization technology, therefore these modern facilities can not be fully utilized, thereby leading to high resource waste.

Backward Management Information Technology Construction. Colleges actively play advantages of information knowledge and technology with extensive application of information technology in the field of file, thereby greatly reinforcing file information technology construction. Profound influence should be produced for construction and management for college file work. However, current college file information technology construction is still in the initial stage. Many related problems should be focused, studied and solved, basic information equipment construction, archives network system construction, electronic document management system construction, digital archives construction, file network construction, archivist information technology quality education and many problems should be further improved.

\section{File Management Improvement Measures}

Strengthening File Management Awareness. Competition mechanism is introduced in file management for enhancing sense of competition. Post responsibilities, work performance and economic interests are combined for promoting improvement in file department efficiency. Meanwhile, scientific awareness of file management personnel is enhanced for guiding practical work and promoting the work. Colleges should take the initiative to apply modern management techniques and tools in file management work. Finally, sense of service also should be strengthened. College file management serves the society. Whether file works can be developed forwards smoothly or not for maximizing its value greatly depends on whether social service is regarded as important part in file management or not.

Perfecting File Management System. Updating of file management system is an important measure to improve file management in China. Foundation can be laid for college file management work by constructing management system adapting to time features. Firstly, college file management department should be separated from college office in the aspect of setup of file management mechanisms in colleges, mechanism department with corresponding powers should be formed singly. Its institution function, staffing, job responsibilities and assessment methods should be regulated in details. Secondly, management system of college file management should be improved. College file management should be mainly refined and regulated in several aspects of file data collection and sorting, archiving and storage, achieves information technology equipment maintenance, file information safety state, file department service, personnel training, etc., thereby ensuring smooth and ordered development of file management work in the colleges.

Strengthening File Resource Information Sharing. Universal application of computer has changed the static and unchanging information existence mode, thereby replacing dynamic, multi-faceted and multi-level information center. Information management should be realized aiming at college file management as soon as possible from management point of view. Computer retrieval system should be established immediately. Relational database with college file own features is established according to file level or file-level directory, thereby reaching high efficiency of file information retrieval, and improving recall ratio and precision. File management staff should take the lead for realizing transition from static information keeping state to dynamic element. File management work and utilization work should be operated in network, thereby actually realizing file information management. Realization of file knowledge sharing is the final objective of file knowledge management, which also acts as contact link among file department, other departments and external word. File knowledge intelligence services can be realized by building knowledge repository, providing knowledge navigation, knowledge consulting and other modes. The service mode can be realized more easily under gradually growing environment. Knowledge transfer and sharing can be realized through constructing campus internal network. Internal network is constructed 
on the basis of network interconnection, internal information islands which are respectively closed originally can be interconnected, thereby realizing knowledge information transfer and service sharing.

Strengthening training of teaching file management personnel. Quality of teaching file management personnel directly determines quality of college teaching management. Firstly, training of ideological and moral cultivation should be strengthened, post dedication should be promoted, service awareness should be reinforced, the legal awareness should be strengthened, so that 'legitimate file management' can be achieved for maintaining file safety. Teaching file management should be accompanied by college file management modernization progress with modernization of file management. Higher requirements are proposed for quality of teaching file management personnel. Colleges should improve job training, improve service quality, regularly train teaching file management personnel, personnel should study and discuss in a targeted mode, thereby improving file professional theoretical level and file management professional skills. They should be organized for learning related systems and regulations about teaching file management, thereby improving ability of applying specification, computer application and network management knowledge learning can be reinforced, thereby improving their professional skills. Post exercise should be implemented, post specification should be formulated, thereby improving their learning motivation and enthusiasm.

Improving File Management Environment. There are many links from electronic file formation to archiving. If on link has unclear responsibility, loose system and insufficient consideration, file document originality can be lost. Therefore, a set of scientific, qualified and strict management system should be set up with clear responsibilities. Authority should be set to concrete personnel (or posts) clearly. School file department should make clear electronic file archiving time, scope, technical environment and related methods about version format and test data. Personnel should comprehensive and carefully check during archiving. Information distortion in the conversion process should be prevented during sorting, and use and management records of electronic files should be perfected during use. After electronic files are formed, formats and carrier should be necessarily converted regularly, file should be backed up, thereby electronic files can be under safe security state. Management of electronic documents and electronic files should be strengthened, which is beneficial for linking file modern management and office automation, file work can provide efficient services for all departments in the school immediately, opportunities can be controlled, office automation level can be utilized for promoting file management progress. Digital file information resource construction can be moved to file formation departments forwards, thereby greatly reducing the labor intensity of file management work, simplifying work procedures, and improving work efficiency and quality.

\section{Summary}

Implementation of file work and realization of file management modernization belongs to a long-term, hard and challenging project, the project can be realized depending on objective control of national and file administrative authorities as well as powerful support of information department as well as attention and effort of grassroots and own departments, thereby realizing information resource sharing in all fields of the society, thereby better exerting the role of file management in college management

\section{References}

[1]. Xiaoqing SUN. Universities in the new period the exploration of the archives management problems, J. Journal of Educational Institute of Jilin Province. 2012,28(2):137-138.

[2]. Guiying Zhu. Starategy and Analysis of Main Problems in College Documents Management, J. Journal of Huaiyin Institute of Technology.2013,12(4):80-81.

[3]. Qing XIA. The system of file management in Colleges and Universities, Nanjing, 2002. 
[4]. Fang YANG. Analysis on the Problems in and Countermeasures for University Archives Management in Knowledge Economy Age, J. Sci-Tech Information Development \& Economy.2011,21(2):137-138.

[5]. Aaron, D, Purcell. Academic Archives: Managing the Next Generation of College and University Archives, Records, and Special Collections, J. The Journal of Academic Librarianship. 2012,38(5): 316-317.

[6]. Yongfu CHEN. Construction for the Archives Management System and Pattern of Enterprise in the New Period. Anhui University, 2007.

[7]. Xiao-juan LIN. Construction of archives management informatization, J. Information Technology.2012,7:56-58.

[8]. Airong CUI. Analysis on the Modernization of Archives Management, J. Career Horizon.2012,1:111-112.

[9]. Baohu DENG. Discussion on Construction of College Archives Management Informationization and Networking, J. Journal of Guangxi Economic Management Cadre College.2008,3:12-13.

[10]. Hui zhu MIAO. Talking about Doing Well the Records Management of University in the New Period through Renewing the Conception t, J. Sci-tech Information Development \& Economy.2005,5(7):15-16. 